\title{
39. EL TRIBUNAL CONSTITUCIONAL
}

PEDRO J. TENORIO SÁNCHEZ

Profesor Titular de Derecho Político

UNED 


\section{SUMARIO}

I. Consideraciones PReliminares.-II. Composición.--III. Las COMPEtencias del Tribunal Constitucional. Funciones. Balance.-A) Razón de ser de la institución. B) Competencias expresamente enumeradas en la Constitución. a) Amparo ante el Tribunal Constitucional. b) Recurso de inconstitucionalidad. c) Cuestión de inconstitucionalidad. d) Conflictos de competencias entre Estado y Comunidades Autónomas y de éstas entre sí. C) Otras competencias aparecidas en el desarrollo de la Constitución. D) Otras competencias no existentes. Su conveniencia. IV. CONSIDERACIONES FINALES. 


\section{EL TRIBUNAL CONSTITUCIONAL}

POR

PEDRO J. TENORIO SÁNCHEZ

Profesor Titular de Derecho Político

UNED

\section{CONSIDERACIONES PRELIMINARES}

Parece inevitable hacer algunas consideraciones previas que delimiten el objeto de nuestra intervención por obvias que resulten.

Es la primera que, por más que nuestro Tribunal haya padecido fuertes críticas, por más que parte del entusiasmo que inicialmente suscitó se haya apagado, por más que desde un punto de vista puramente hipotético la justicia constitucional podría ser concentrada y ser distinta a la nuestra, o no ser concentrada, o hasta no existir (como ocurre todavía en países europeos de nuestro mismo ámbito político, como es el caso de Bélgica) nuestro Tribunal Constitucional ha arraigado en nuestro sistema. Parece que no es él, no es el Título IX, el que recibe críticas que justifiquen la apertura de un proceso de revisión constitucional.

Sin embargo, el objeto de este Curso es la valoración del texto constitucional durante estos trece años de vigencia y la presentación de eventuales propuestas de reforma redactadas con la forma y el estilo normativo.

Entendemos que en caso de apertura de un proceso de revisión constitucional dos serían las cuestiones que podrían plantearse desde un punto de vista más o menos realista. Por un lado, las posibles reformas que conlleve el proceso de integración europea. Por otro, en caso de refor- 
ma de la Constitución, es el Senado el punto más indiscutido, aquel sobre el que probablemente podría realizarse una revisión constitucional sin cambiar nuestra Constitución en sentido material y sustancial y sin agrietar el difícil consenso conseguido en torno a ella.

Esta ponencia va a partir en definitiva de que el Título IX no es particularmente discutido; de que una eventual reforma constitucional se referiría al Senado; de que esa reforma giraría en torno a lo propuesto en este mismo Congreso por el Profesor TORRES DEL MORAL.

\section{COMPOSICIÓN}

En cuanto a la composición del Tribunal Constitucional, la reforma del Senado como auténtica Cámara de representación del pueblo español organizado en Comunidades Autónomas (empleando la expresión de TORRES DEL MORAL) permitiria, si no colmar, al menos acaso satisfacer parcialmente una reivindicación que se repitió una y otra vez a lo largo del debate constituyente: la participación de las Comunidades Autónomas en la elección de los miembros del más alto intérprete de la Constitución.

A este propósito creemos que la actual composición del mismo debe ser examinada a la luz de una distinción conceptual que es frecuentemente utilizada por la propia jurisprudencia de nuestro Tribunal Constitucional. Nos referimos a la distinción entre el Estado Central y el Estado sin adjetivos que comprendería tanto al Estado Central como a las Comunidades Autónomas. Pues bien, si proyectamos estos conceptos sobre el actual sistema de designación, resulta un cierto desequilibrio en beneficio de instancias que podemos considerar Estado Central. En efecto, cuatro magistrados son nombrados por el Congreso de los Diputados, órgano del Estado Central, dos más por el Gobierno, órgano del Estado Central, dos más por un órgano como el Consejo General del Poder Judicial que podemos considerar del Estado en la medida en que la mitad de sus miembros son elegidos por el Senado. Sólo cuatro miembros del Tribunal Constitucional son elegidos por el Senado, por el órgano del Estado que es reclutado a través de las Comunidades Autónomas u otras unidades territoriales de extensión más reducida que el Estado. 


\section{LAS COMPETENCIAS DEL TRIBUNAL CONSTITUCIONAL. FUNCIONES. BALANCE}

\section{A) Razón de ser de la institución}

Tenemos un Tribunal Constitucional en cuyo diseño nos hemos beneficiado tanto de los estudios teóricos anteriores como de la experiencia histórica nacional y extranjera.

El elenco de sus competencias es el precipitado de la experiencia en justicia constitucional acumulada en la cultura jurídica occidental. Ello acaso produce dificultades desde el punto de vista teórico y dogmático. En sentido estricto sus actuaciones en vía de recurso de inconstitucionalidad deberian regirse por criterios considerablemente distintos de los que regirían las actuaciones jurisdiccionales en sentido estricto: amparo o conflictos. En un ámbito se trata de comparar dos normas en abstracto mientras que en el otro el juzgador puede $y$ debe tener en cuenta los resultados de su sentencia. Evidentemente la justicia constitucional no actúa con semejante pureza, pero lo que es importante señalar es que en su conjunto ha cumplido con su cometido institucional. Esto último requiere alguna explicación.

La considerable amplitud con que se configura el recurso de amparo en nuestro sistema viene a ser un reforzamiento de la misión histórica de la justicia constitucional en Europa. Ésta parece llamada en nuestro siglo a hacer normativa, plenamente vigente la llamada parte dogmática de las Constituciones, los derechos y libertades, frente a Poderes Judiciales heredados de momentos autoritarios en los que o no existía Constitución o ésta era considerada programática. Baste recordar al efecto la experiencia italiana: entre 1948, año en que entró en vigor la Constitución actual, hasta 1956, en que se dicta la primera Sentencia del Tribunal Constitucional, el Poder Judicial había considerado programática la parte dogmática de la Constitución negándole incluso alcance derogatorio respecto de la legislación anterior. El Tribunal Constitucional italiano en su primera Sentencia de 14 de junio de 1956 hubo de arrogarse el monopolio en el control de la constitucionalidad de la legislación no sólo postconstitucional sino también de la preconstitucional.

Ahora bien, una vez aceptada de forma indiscutida la eficacia normativa de la parte dogmática de nuestra Constitución por el Poder Judicial, a lo que estamos asistiendo es más bien a una aplicación destalentada, desordenada, prolija, excesiva de algunos derechos (en particular del 
reconocido en el artículo 24 en su primer inciso, el derecho a la tutela judicial efectiva) que está obligando al Tribunal a sustituir a los órganos jurisdiccionales ordinarios. Esta interpretación excesivamente amplia del inciso primero del artículo 24, comienza a sembrar inseguridad jurídica. Probablemente no sucederia nada si desapareciera y, en consecuencia, convendría interpretarlo como mera introducción al conjunto de derechos que aparecen enumerados a lo largo del propio artículo 24 . No olvidemos que entre esos derechos está nada menos que la prohibición de indefensión o el derecho al proceso con todas las garantías, cláusulas que serian suficientes para importar, adaptándola, toda la jurisprudencia del Tribunal Supremo de Estados Unidos en torno al «debido procedimiento legal». Ya dicha jurisprudencia presenta suficientes dificultades como para tener en nuestro texto constitucional tres cláusulas dentro de las cuales podría incluirse parcialmente o en su totalidad.

\section{B) Competencias expresamente enumeradas en la Constitución}

\section{a) Amparo ante el Tribunal Constitucional}

Basten las consideraciones hechas anteriormente con motivo de la razón de ser de la institución.

b) Recurso de inconstitucionalidad

Por lo que se refiere al control abstracto por vía de recurso de inconstitucionalidad no es objeto de esta ponencia traer a colación casos particularmente discutidos que están en la mente de todos. Recordemos al respecto la máxima de Derecho angloamericano: "hard cases make bad Law”. En su conjunto, la regulación de esta competencia no ha sido objeto de graves críticas. Ahora bien, supuesta una reforma de la Constitución que afectara al Senado, habría que redactar de nuevo el precepto relativo a la legitimación para plantear el recurso.

Según la ponencia del Profesor TORRES DEL MORAL, el artículo 161,1 a) quedaría como sigue:

"Para interponer el recurso de inconstitucionalidad, el Presidente del Gobierno, el Defensor del Puebio, 50 diputados, 20 senadores, los Gobiernos 
autonómicos, y los Parlamentos autonómicos. El recurso interpuesto por senadores y por órganos autonómicos sólo puede versar sobre materias que afecten a la organización territorial del Estadon.

Queremos, no obstante, expresar una duda respecto de la limitación de la legitimación de los senadores para recurrir sólo en materias relativas a la organización territorial del Estado. Si el senador no está ligado por mandato imperativo, si el Senado es órgano del Estado como un todo (no del Estado central), parece que a los senadores no les es ajeno ningún tipo de inconstitucionalidad. La limitación, por tanto, debería afectar tan sólo a los órganos legitimados de las Comunidades Autónomas. Sobre este punto, por lo demás, como manifiesta en su ponencia el Profesor TORRES DEL MORAL, existe suficiente jurisprudencia constitucional.

\section{c) Cuestión de inconstitucionalidad}

Íntimamente relacionada con el recurso de inconstitucionalidad, interesa subrayarlo, aparece la cuestión de inconstitucionalidad del artículo 163 de la Constitución española. Respecto de la misma haremos tres rápidas observaciones.

La primera, consistiría en recordar un dato de hecho: las cuestiones de inconstitucionalidad, poco numerosas en un principio, manifiestan una ininterrumpida tendencia a aumentar en su número.

La segunda observación hace referencia a la falta de acceso de las partes del proceso principal al proceso que se desarrolla ante el Tribunal Constitucional. Se trata de algo que ha sido criticado desde una perspectiva procesalista, perspectiva que, en nuestra opinión, no es la que debe adoptarse en este caso. Lo que se ventila ante el Tribunal Constitucional es la compatibilidad en abstracto entre dos normas y por lo tanto no se alcanza a comprender por qué tienen que participar en dicho proceso las partes del proceso que se sustancia ante la jurisdicción ordinaria. Por lo demás, no se trata de algo que esté incluido en la Constitución sino tan sólo en la Ley Orgánica del Tribunal Constitucional y que por lo tanto excede del objeto de esta ponencia.

La tercera observación es relativa a los efectos sobre el proceso principal del planteamiento de la cuestión de inconstitucionalidad ante el Tribunal Constitucional. Acaso en este punto resulta necesario un retoque del texto constitucional. Éste afirma que los efectos "en ningún caso serán suspensivos». La jurisprudencia constitucional ha tenido que dar interpre- 
taciones forzadas a este inciso. Así, por un lado, se ha afirmado que no produce efectos suspensivos salvo respecto de la celebración de la vista oral; por otro lado, ha habido que aceptar efectos suspensivos no sólo con respecto a la aprobación de la sentencia sino a la de otros actos de carácter similar a la misma. En definitiva, probablemente la supresión de este último inciso supondria muchas más ventajas que inconvenientes.

\section{d) Conflictos de competencias}

La tercera competencia que enumera el artículo 161 de la Constitución española, concretamente en el apartado 1,c), son los que llama "conflictos de competencias entre el Estado y las Comunidades Autónomas o de los de éstas entre sín. Y hay que resaltar la expresión los que llama, porque junto a estos conflictos en sentido estricto, o si se quiere técnico, la conflictividad entre éstas personas jurídico-públicas de carácter territorial puede manifestarse por otras dos vías ante el Tribunal Constitucional. Una la hemos visto con anterioridad: los recursos de inconstitucionalidad. Otra es la establecida en el artículo 161, apartado 2:

«El Gobierno podrá impugnar ante el Tribunal Constitucional las disposiciones y resoluciones emanadas por los órganos de las Comunidades Autónomas. La impugnación producirá la suspensión de la disposición o resolución recurrida, pero el Tribunal, en su caso, deberá ratificarla o levantarla en un plazo no superior a cinco meses".

La delimitación de estos procedimientos entre sí, como se sabe, presenta múltiples problemas. Uno de ellos, el de si la ley puede o no ser objeto de conflicto de competencias.

Pero aquí lo que nos interesa destacar es la naturaleza particularmente difícil de armonización de la facultad del artículo 161,2 con la posibilidad de acudir ante la Jurisdicción Contencioso-Administrativa. Distinción particularmente relevante si tenemos en cuenta que en este caso no dispone el Gobierno de la facultad de provocar una suspensión automática que podría convertirse en indefinida.

Resulta significativo que a lo largo del proceso constituyente el Gobierno se ocupara de mantener este precepto.

Tanto la doctrina (FERNÁNDEZ FARRERES, MEILÁN GIL) como la jurisprudencia han subrayado que esta vía sólo puede ser admisible cuan- 
do las disposiciones sin fuerza de ley o resoluciones de los órganos de las Comunidades Autónomas adolezcan de un vicio de constitucionalidad y no de mera legalidad y dicho vicio sea distinto de la infracción o vulneración del orden constitucional de distribución de competencias entre el Estado y las Comunidades Autónomas (Sentencias del Tribunal Constitucional $44 / 86$ y $64 / 90)$.

A juzgar por el número de asuntos planteados y pendientes no se puede decir que el Tribunal Constitucional haya permitido al Gobierno abusar de esta prerrogativa.

Aun así, revela una desconfianza hacia las Comunidades Autónomas, una identificación del Estado con el Estado central, que acaso convendría superar. Tres opciones caben para ello: la primera, prescindir de este cauce; otra, otorgarlo por igual a Estado y Comunidades Autónomas; y, por último, otorgarlo a Estados y Comunidades Autónomas pero suprimiendo la suspensión automática, es decir, ésta habría de ser acordada en concreto por el Tribunal Constitucional. Esta última es la que nos parece mejor solución. $Y$ entonces tendríamos un artículo 161,2 del siguiente tenor:

"Tanto el Gobierno como los órganos colegiados ejecutivos de las Comunidades Autónomas podrán impugnar disposiciones y resoluciones de otros órganos supremos ejecutivos del Estado y de las Comunidades Autónomas por vicios de inconstitucionalidad, diferentes del quebrantamiento del orden de competencias constitucionalmente establecido entre Estado y Comunidades Autónomas. La ley establecerá la posibilidad por parte del Tribunal Constitucional de acordar la inmediata suspensión del acto recurrido".

Una manera de convertir este control en control del Estado (no del Estado central) sobre las Comunidades Autónomas se desprende de la propuesta avanzada por TORRES DEL MORAL:

"El Gobierno, con la aprobación del Senado ...".

Esta propuesta, teniendo esta indudable ventaja, en cambio, quiebra, a nuestro parecer, una convención implícita o subyacente en la configuración de la justicia constitucional. La impugnación se filtra por un trámite político y no jurídico. Es más coherente con la pretensión de judicializar el control de constitucionalidad no interponer un filtro político, sino uno que al menos pretende ser jurídico: el propio Tribunal Constitucional. 


\section{C) Otras aparecidas en el desarrollo de la Constitución}

El artículo $161,1, d)$ de la Constitución establece la competencia del Tribunal Constitucional para conocer de las demás materias que le atribuyan la Constitución y las Leyes Orgánicas.

Esta proposición abierta que la doctrina en general acogió favorablemente, ha permitido que la Ley Orgánica del Tribunal Constitucional y otras Leyes Orgánicas amplíen las competencias de nuestro Alto Tribunal. En particular cabe señalar:

1) Conflictos entre órganos constitucionales: artículos 73 a 75 de la LOTC; artículo 8,1 de la LO 7/88 del Tribunal de Cuentas (desarrollado en el artículo 3 de la Ley $7 / 88$ de funcionamiento del Tribunal de Cuentas).

2) Recurso previo de inconstitucionalidad sobre proyectos de leyes orgánicas o de estatutos de autonomía (artículo 79 LOTC derogado por LO 4/1985).

3) Tres recursos que en realidad, como ha señalado PÉREZTREMPS, no son sino reglas procesales especiales del recurso de amparo en determinadas materias: en primer lugar, el recurso de la Ley Orgánica del Régimen Electoral General (artículos 49,3 y 114,2); en segundo lugar, el amparo en materia de objeción de conciencia (LO 8/1984); por último, el amparo contra decisiones de inadmisión de iniciativa legislativa popular (artículo 6 LO 3/1874).

Por lo que se refiere a los conflictos entre órganos constitucionales, la regulación de la LOTC establece un elenco de sujetos legitimados y una concepción del objeto del proceso que convierte esta institución en algo virtualmente estéril. Si se pretende que en realidad empleen este recurso los sujetos realmente interesados en ello, entonces convendría volver la mirada hacia la regulación que nos ofrece la Ley Fundamental de Bonn en su artículo 93,1,1), con lo que el precepto correspondiente de nuestra Constitución o de nuestra Ley Orgánica entregaría competencias a nuestro Tribunal Constitucional para resolver:

"Conflictos sobre el alcance de las atribuciones o derechos o deberes constitucionales de un órgano constitucional o de partes de tales órganos dotadas de atribuciones o derechos propios por la Constitución o por la 
Ley Orgánica o reglamento interno, en su caso, de dicho órgano constitucional».

Con análoga regulación, en Alemania se entiende que los partidos, los grupos parlamentarios, e incluso los miembros de las Cámaras singularmente considerados, pueden plantear conflictos ante el Tribunal Constitucional.

Por lo que se refiere al recurso previo de inconstitucionalidad, fue suprimido en 1985 con referencia a las Leyes Orgánicas, quedando sólo como posible objeto del mismo los tratados internacionales. En cuanto a la existencia del mismo con referencia a leyes, hay que hacer dos observaciones de distinto carácter. La primera, que se suprimió por razones políticas, es decir, para evitar un uso obstruccionista del mismo por parte de la oposición. La segunda, de carácter jurídico, sería reconocer que dicha supresión es conforme con la naturaleza de nuestra justicia constitucional: nuestro Tribunal Constitucional no es un órgano político con cuya voluntad pueda integrarse una decisión de naturaleza política, sino que es un órgano que administra justicia y que por lo tanto, en principio, no adopta decisiones con criterios políticos.

Por lo demás, la supervivencia de este recurso con referencia a los tratados internacionales habrá sido tratada por otros ponentes, dada la reciente utilización de este mecanismo por primera vez con motivo de la ratificación de los acuerdos de Maastricht.

\section{D) Otras competencias no existentes. Su conveniencia}

Otras competencias que aparecen asignadas a algunos Tribunales Constitucionales de ordenamientos extranjeros $y$ que, en cambio, no aparecen en el nuestro son, de manera más o menos periódica, planteadas como una laguna en nuestro sistema. Mencionaremos tres:

1) La llamada administración de justicia política, es decir, la competencia consistente en juzgar a determinadas autoridades aforadas, como puede ser el caso del Jefe del Estado. Entendemos que la materia queda suficientemente regulada en nuestra Constitución con la afirmación de la irresponsabilidad del Rey y del carácter aforado de determinados Altos Cargos del Ejecutivo. 
2) Se planteó en algún momento por nuestra doctrina (A. GARCÍA CUADRADO) la conveniencia de establecer un control de constitucionalidad de los reglamentos que desarrollaron directamente la Constitución. La evolución posterior del Ordenamiento (LO del Poder Judicial) y de la jurisprudencia, que han permitido el control de constitucionalidad de todo tipo de reglamentos por parte de la jurisdicción contencioso-administrativa, hacen que en el momento en que se escriben estas líneas sea innecesario añadir semejante competencia a las que ya tiene nuestro Tribunal Constitucional.

3) Otra cuestión que se plantea de modo recurrente es la conveniencia de entregar a nuestro Tribunal Constitucional el control de la constitucionalidad de los partidos políticos. Diremos al respecto, muy sintéticamente, que la consideramos inoportuna en este momento e incongruente con el concepto de democracia. Inoportuna porque a estas alturas probablemente lo es incluso en ordenamientos de países especialmente atribulados en este ámbito, como es el caso conocido de Alemania. Incongruente con el concepto de democracia porque si ésta quiere ser tal debe ser tan amplia como para que dentro de ella quepan sus enemigos.

\section{CONSIDERACIONES FINALES}

No podemos cerrar una contemplación de conjunto de nuestra justicia constitucional sin mencionar un fenómeno cada vez más extendido. A pesar de que las leyes configuren un sistema de justicia constitucional concentrado, no se puede ignorar que opiniones doctrinales muy autorizadas han afirmado la conveniencia.de añadir a este tipo de control de constitucionalidad el control de constitucionalidad difuso. La argumentación que se hace al respecto, como se puede suponer, está emparentada con la que en su día llevó al Poder Judicial norteamericano a asumir este tipo de competencias. En nuestra opinión, sin un cambio legislativo no es posible la incorporación de esta forma de control de constitucionalidad en nuestro Ordenamiento. 